\title{
Green Out of the Blue, or How (Not) to Deal with Overfed Oceans
} An Analytical Review of Coastal Eutrophication and Social Conflict

\author{
Alix Levain, Carole Barthélémy, Magalie Bourblanc, \\ Jean-Marc Douguet, Agathe Euzen, and Yves Souchon
}

ABSTRACT: Despite causing harmful impacts on coastal communities and biodiversity for a few decades, eutrophication of marine systems has only recently gained public visibility. Representing a major land-based pollution, eutrophication is now considered the most striking symptom of intractable disruption of biogeochemical nutrient cycles at a global scale. The objective of this article is to analyze multi-scale dynamics of the problematization and regulation of ocean overfertilization. To do so, we build on a comprehensive literature review of previously published works that address the sociopolitical dimension of eutrophication issues and whose visibility we analyze with a critical perspective. We identify three stages that characterize the social history of marine eutrophication and how it was handled by public authorities. Although social mobilizations focus on emblematic sites, conflicts directly related to eutrophication symptoms spread in diverse hydro-social configurations. We conclude with a typology of four configurations associated with enduring nutrient pollution: noisy, overwhelming, silenced, and disturbing eutrophication.

KEYWORDS: coastal eutrophication, environmental change, hydro-social configuration, public problems, nutrient-based pollution, social-environmental conflicts

Despite harmful local consequences on coastal communities and biodiversity for many decades, eutrophication of marine systems due to high levels of nutrient loading of human origin has only recently gained public visibility (Diaz and Rosenberg 2008; Nixon 2009; UN 2017). A major type of land-based pollution, it is now considered the most striking symptom of difficult-to-reverse disruptions of biogeochemical nutrient cycles at the global scale (Steffen et al. 2015), because of massive phosphate ore extraction and the industrial synthesis of reactive nitrogen, the main drivers of harmful algal blooms in the sea (Glibert et al. 2018). Social sciences have much to contribute to understanding the overfertilization of marine environments due to human activities: like many contemporary environmental problems, its embeddedness in economic development dynamics makes it a "wicked" issue (Rittel et al. 1973), with social complexity, multi-scale dynamics, changing perceptions, path dependency, and power relations forming a wall offering little purchase for transformative action (Jentoft and Chuenpagdee 2009; Le Moal et al. 2019; Thornton et al. 2013).

This wicked dimension goes along with the difficulty in acknowledging and agreeing on the distribution, scale, nature, and intensity of social consequences to and impacts on local people; 
it largely characterizes coastal communities' experience of environmental change management today (Pokrant and Stocker 2011). Indeed, the negative experience of local people has usually been insufficient to trigger stringent public policies, since the lack of effective public action is often presented as the result of local antagonisms and persistent scientific uncertainties. This occurs even though eutrophication management has a long and complex history, resulting in the coexistence of diverse degrees of social visibility of the phenomenon and widespread but scattered local struggles. Marine ecologists have long emphasized this lack of public action (Larson 1996; Nixon 2009), which has provoked endless debates over science-policy interactions but also over the lock-in effects of sociotechnical systems, in which interactions among technological, social, and managerial components of a given system contribute to its long-term stability (Callon 1991; Geels 2004). This situation also raises the question of what scale and resolution can most accurately capture the complex and contrasting social experiences of such a distributed and heterogeneous syndrome as marine eutrophication.

This article builds on a literature review and on selected concepts from political ecology to analyze the relationship between the social experience of environmental change and social conflict in the context of persistent but evolving scientific uncertainty and attempts at management. To do so, we first address this complex landscape by drawing on an extensive international overview of formerly scattered works that explicitly address sociopolitical dimensions of ocean overfertilization. We analyze these heterogeneous materials and question their diversity with a critical perspective, since we acknowledge an epistemic, methodological, and conceptual gap between this corpus and insights from political ecology on water issues, which has rarely addressed marine systems to date. We propose an initial step to bridge this gap by addressing the diversity of hydro-social assemblages associated with coastal eutrophication.

We then draw on the subset of the literature that addresses coastal eutrophication with both diachronic and critical perspectives. We sequence the trajectory of eutrophication as a social problem into three major periods from the beginning of the twentieth century to the present. By doing so, we provide evidence of specific framing activities and mechanisms for acquiring social visibility associated with coastal eutrophication issues, and analyze the multi-scale dynamics of framing ocean overfertilization as a global problem. Finally, we focus analysis on the most recent period we identified: the beginning of the 2000s to the present. Expanding the concept of hydro-social assemblages to seawater ecosystems, we develop a typology of configurations associated with coastal eutrophication, based on transversal analysis of case studies of enduring conflicts related to land-based nutrient pollution. Through three sets of criteria (primary visibility, secondary visibility, regulation dynamics), we characterize four configurations: noisy, overwhelming, silenced, and disturbing. This comprehensive approach ultimately leads us to question how oceanic features accentuate the challenge of dealing with nutrient pollution in the context of global change.

\section{How Social Scientists Address Coastal Eutrophication: From Contextual Approaches to Critical Perspectives}

\section{An Unfinished Encounter between Social Science and the Enrichment of Marine Waters}

From 2016 to 2018, a multidisciplinary group of expert researchers from a variety of backgrounds was asked by the French ministries of the environment and agriculture to review the current state of research on eutrophication, with special emphasis on land-water interactions along the land-water-sea continuum. A national charter signed by the National Center for Scientific Research (CNRS), the French Institute for Marine Research, the National Institute for 
Agricultural Research, and the National Institute of Science and Technology for the Environment and Agriculture governed this joint scientific assessment. The experts' work drew on a bibliographic corpus of about four thousand references selected from the Web of Science composed of peer-reviewed scientific articles and, for several topics, technical or scientific reports and legal texts.

The authors of this article served on an expert panel responsible for a comprehensive review of social and political dynamics associated with eutrophication issues. The panel's composition and scope reflected the objective to cover a wide range of social science disciplines and perspectives, including institutional economy, social anthropology, sociology, and political science. Our group of social science experts struggled to comply with the knowledge framework imposed by the expert assessment in which we were involved. When we searched scientific databases using the most obvious keywords, we faced either a "silent" or an excessively "noisy" atmosphere, with no clear or well-defined research landscape, and even less well-defined scientific communities. Specifically, our search of four major bibliographic databases (Thomson Web of Science, JSTOR, Scopus, and Springer) identified 2,782 references of potential interest in the field of social sciences broadly speaking. However, none of them used "eutrophication" in the title, and only 14 used it as a keyword. A detailed review showed that articles rarely used the word eutrophication itself, or seemed to identify nutrient-based pollution as a significant aspect of social life in previously identified eutrophic zones.

In fact, most situations that environmental scientists had documented were not studied by social scientists, even when harmful effects on social communities had been emphasized by existing literature. Although these somewhat disappointing results were practically unavoidable in an interdisciplinary assessment framed by the quest for symmetry among types of knowledge, they were expected and explainable from both epistemological and historical viewpoints. Social scientists build their arguments on case studies and/or social actors' problematization of more accessible concepts such as water quality, biological invasions, legal devices, and public policies. Consequently, social science articles rarely described underlying ecological concepts or mechanisms; instead, they kept these concepts as background context and focused on other problems or more generic scientific questions.

Nonetheless, comprehensive analysis of the articles revealed that many of them had nutrient pollution and eutrophication symptoms as their background, but rarely as a main topic, and it found that coastal eutrophication appeared to be addressed through three main prisms (Levain et al. 2017). The first considers the trajectory of nutrient-based pollution as a public problem in industrialized countries; it is adopted mainly by historians, sociologists, and political scientists who study local cases in Europe and North America within the past one hundred years, although few studies adopt such a long-term perspective (e.g., for riverine countries of the Baltic Sea; Laakkonen and Laurila 2007; Löwgren et al. 1989). In this prism, the specificity of coastal social-ecological systems and the materiality and diversity of eutrophication symptoms remain peripheral dimensions, while emphasis is placed on governance systems and the trajectory of water pollution management upstream.

The second prism addresses the mechanisms and diversity of perceptions or social representations of water quality and pollution; it is adopted by heterogeneous works in social psychology (e.g., Moser 2004) and economy (Artell et al. 2013; Söderqvist 1998). Cultural and social anthropology (Dalla Bernardina 2010; Le Chêne 2012; Levain 2014, 2017; Paolisso and Maloney 2000) and environmental geography (e.g., Cadoret 2009; Freitag 2014) share a similar focus on the materiality of eutrophication symptoms and the diversity of individual experiences, but provide supplementary materials on specific surrounding political, social, or ecological systems that help historicize the trajectory of coastal eutrophication as an issue for local people. Most 
of these works rely on empirical data collected from areas where domestic recreational uses of coastal waters are particularly well developed and where eutrophication has been a mediatized environmental issue for at least two decades.

The third prism addresses mainly eutrophication with a highly contextualized, applied and interdisciplinary research perspective; it is adopted by a variety of scholars who endorse a "sustainability science" label, in works published after 2005 (e.g., Bailey et al. 2015; Lundberg 2013). This prism focuses on describing the complexity of responses of social-ecological systems to massive anthropogenic nutrient inputs, on governance issues and on stakeholder participation to river-basin governance (e.g., Franzén et al. 2011; Nunneri and Hofmann 2005). Recent works endorse an analytical framework for ecosystem services to assess impacts of coastal eutrophication, while emphasizing the need for nonmonetary assessment and qualitative inquiry to approach the cultural dimension of environmental degradation (Kermagoret et al. 2019; Willis et al. 2018).

\section{Interpreting the Enduring Division between Critical Approaches and Sea-Related Issues}

Within this corpus, critical social science literature that explicitly addresses the history, nature, and magnitude of coastal eutrophication phenomena and changes remains scarce. Clues for understanding this research gap include general arguments about critical social sciences' well-known difficulties in becoming involved with water research programs, such as the stilldominant deterministic paradigm of social engineering in water research and management (Mollinga 2008), or the wicked nature of water problems, especially the tension between abstract scientific and site-specific knowledge (Adger et al. 2001; Freeman 2000) involved in both qualitative social research and experiential knowledge of the communities concerned (Barth 2002).

More topic-specific clues should also be considered, such as the persistent disconnection between water and marine social studies and the overlooked nature of aquatic fertility issues, even in the fields of political ecology and science and technology studies (STS), in which water has been a preferential and intensively addressed theme. Contributions of social scientists to contemporary ocean science remain rare, if not marginal, which is closely related to the still-dominant conceptualization of the ocean as unpopulated space (Bennett 2019; Shackeroff et al. 2011) and to the enduring division between marine and terrestrial scopes of empirical surveys by social scientists. Contemporary appeals and attempts to bridge this gap generally focus on fisheries and aquaculture activities, communities and multi-scale management (e.g., Berkes 2015; Longo et al. 2015), more than on seawater resources and uses. However, they strive to consider the land-sea continuum as a social issue to be addressed with social sciences' concepts and methods (Mazé et al. 2017). Nonetheless, regulating cross-system threats such as coastal eutrophication raises specific challenges such as determining boundaries, addressing crossscale effects and accessing knowledge (Pittman and Armitage 2016), all of which lie at the core of the political ecology of water (Bakker 2012; Forsyth 2004; Krause and Strang 2016).

The transformative properties of oceans' ecological mechanisms also tend to maintain a cultural and epistemic discontinuity between freshwater and seawater (Levain and Laval 2018). The latter, as Veronica Strang points out, is associated in many epistemologies with the ocean's representation as a "great sink," where everything is washed away, absorbed and regenerated, which is a "dangerous illusion" regarding marine pollution (2015: 151). Following this ontological perspective, Stefan Helmreich emphasizes the epistemic ordeals encountered by anthropologists to conceptualize seawater and suggests understanding it as a "potentiality of form and unobtainable flux [that] moves faster than culture" (2011: 132), while emphasizing its material 
and symbolic cultural specificity in the water realm and its heuristic role in contemporary social theory to address the phenomenon of globalization. By doing so, he implicitly highlights its trans-scalar and matrix properties, which can be captured only partially by local management of situated resources. Such anthropological perspectives thus advocate for more inclusive views and provide direct information about the specificity of management of marine water "quality," over which the quality/quantity systemic approach that prevails in freshwater conceptualization and regulation stumbles.

\section{Bridging Scattered Empirical Data by Identifying Hydro-social Assemblages}

Embedded in development dynamics, massive inputs of nitrogen and phosphorus into coastal environments generally result from both massive perturbation of the water cycle upstream and from growing human pressure on coastal environments, which have been broadly characterized as socio-technical historicized assemblages (Barnes and Alatout 2012) or spatialized technonatures (Jepson and Brannstrom 2016) by STS scholars and political ecologists, who aimed to historicize and scale up water problems. In this sense, coastal eutrophication directly echoes the treadmill of production and metabolic analysis of the commodification of nature (Peluso 2012) and its application to water management (Bakker 2005) and marine ecosystems (Longo et al. 2015). A key result of such works is to show how hydrological flow management, water technologies, and power relations are intertwined. For instance, Wendy Jepson and Christian Bannstrom (2016) emphasize that the very definition of water is shaped by technological devices, which help circumscribe the political space and scale for public debate. The concept of "hydro-social cycle," in which water circulation is conceptualized as "a combined physical and social process, as a hybridized socionatural flow that fuses together nature and society in inseparable manners" (Swyngedouw 2009: 56), is instrumental to such a perspective. The concept is based on both a diachronic perspective and the study of highly anthropic, mainly urban, water environments.

The diachronic approach entangled in the "cycle" concept helps capture the historicity of water-pollution management (Linton and Budds 2014). To date, this concept has been used mainly in urban contexts or to address specific hydrological circulation issues and devices, such as flood and drought management, irrigation systems, and dams (e.g., Bijker 2007; Strang 2013; Zimmerer 2011). Addressing water as a hybrid hydro-social flow is key to provide evidence of the intertwined nature of water quality and quantity issues, for instance, to connect the development of eutrophication phenomena to the policy of developing water reservoirs in Sicily to fight drought (Giglioli and Swyngedouw 2008). A decisive challenge for developing this perspective along the land-sea continuum to address the interdependence of terrestrial and aquatic resources (Levieil and Orlove 1990) is to address open-water systems. It implies assuming that current environmental situations make it necessary to reconsider the ocean (or at least parts of it) as part of this socionatural flow. This assumption is heuristic, in the sense that the ocean is a socially and politically constructed and disputed category (Steinberg 2001) and that recognizing the inclusion of marine space in the social space lies at the core of local struggles and publicization of land-based pollution. Coastal eutrophication phenomena not only materialize far beyond coastal marshes but also involve largely unregulated material and immaterial exchanges with the deep sea, which raises questions about the traditional division between freshwater and seawater.

Following this line of research, we dug into our initial corpus to identify and assemble elements that could provide information for a critical perspective. Indeed, this rich but scattered research landscape provided precious information for developing a perspective on the political ecology of water, which we pursued by following two main clues. First, the corpus revealed and 
reflected the various ways in which science and policies interact and align in specific socialecological contexts in time and space. For instance, a striking finding was that coastal and marine socio-ecosystems were clearly underrepresented in the corpus, regardless of the prism chosen, which contrasted with the magnitude and long history of alerts from marine environmental science about seawater quality issues. Another finding was the growing contribution of social scientists to interdisciplinary research programs that addressed ocean pollution during the most recent period. This set of works goes along with a growing claim of environmental scientists that eutrophication phenomena have entered a "third age" in the 2000s, marked by expansion of coastal eutrophication driven by coastal development and the increase in local consequences of global change (Anthony et al. 2009; Le Moal et al. 2019; Rabalais et al. 2009).

At the end of the 2000s, scientific articles emphasized rapid expansion of eutrophic events at the global scale, that few systems were recovering (despite organized public policies in industrialized countries) and that the number of eutrophicated zones was probably underestimated because of insufficient data (Diaz and Rosenberg 2008). Their inventory was associated with a coordinated effort to aggregate historical data on global nitrogen and phosphorous inputs into aquatic ecosystems, including marine ecosystems (Gruber and Galloway 2008). This period is indeed marked by international advocacy efforts that are characteristic of intensive boundary work (Gieryn 1983), in the sense that they tend to expand the legitimacy of scientific discourse in social-political problematization arenas by encapsulating scientific uncertainty, and integrating and comparing global environmental disruptions into new conceptual frameworks and narratives. Thus, comprehensive analysis of the corpus made it possible to inform the evolving science-policy interfaces and the role of knowledge in shaping social-political regulations of eutrophication phenomena, at both local and global scales, thus extending previous attempts to build on the case of the North Sea's "dead zone" since the mid-1980s (De Jong 2006, 2016) and of "green tides" along France's western coasts from the beginning of the 1970s to the present (Bourblanc 2019; Levain 2014).

Second, these works provided precious empirical data from diverse local contexts: urban to rural coastal areas; recreational to extractive sites; highly to poorly regulated hydrological territories; highly visible to discreet eutrophication symptoms; and large, open-sea areas fed by major rivers (e.g., Gulf of Mexico, Bay of Bengal) to small, enclosed saline lagoons. Their comprehensive examination revealed tension between the universal perspective of scientific concepts such as eutrophication and the diversity of hydro-social assemblages encountered within fine-scale descriptions while, at the same time, providing clues for acknowledging and capturing their connections. The review showed that beyond this diversity, case studies are distributed unevenly. A few emblematic sites such as the Baltic and North seas or the Chesapeake Bay have received most of the research effort to date.

Consequently, these cases can be documented and analyzed using a diachronic perspective, due to the existence of historical works-for example, a comparison of the Chesapeake Bay and Scotland that demonstrates the influence of the history of waterbodies and government regimes on nutrient-loss regulation policies (Aukerman 2004); early eutrophication phenomena in urban areas around the Baltic Sea (Arnesen 2001; Hänninen 1992) (Figure 1)-and/or the ability to cross-reference sources over several decades because of a relatively high frequency of research. This diachronic analysis forms the basis of the next section, in which we build on a few emblematic cases (i.e., Baltic Sea, Chesapeake Bay, massive green macroalgal blooms) documented by qualitative social research to define "ages" of eutrophication, provide evidence of successive cycles associated with specific framing activities embedded socio-technical dom- 
inant systems and show how marine eutrophication only recently and partially achieved the status of global nutrient-based ocean pollution.

Building on the about 30 case studies that mention or analyze social conflict associated with marine eutrophication symptoms, we then use a typological approach in order to characterize the variety of social, political and cultural contexts (including social representations of water cycles and land/sea interactions) and to relate them to the diversity of eutrophication symptoms. The main idea is to capture socio-ecological dynamics in deeply anthropic systems with a long history of transformations, uses, management systems, and social and power relations, and to describe interactions between local dynamics and the recent and uncompleted emergence of coastal eutrophication as a global environmental problem. Within this typology, we consider conflicts, public claims and social mobilizations as shaping forces in the description and analysis of hydro-social configurations (Lyytimäki and Assmuth 2015) and their absence as a possible indicator of nonpublic status. This nonpublic status may have different causes, which John Dewey's pragmatic approach to such problems helps to clarify: "Indirect, extensive, enduring and serious consequences of conjoint and interacting behavior call a public into existence having a common interest in controlling these consequences" (2012: 126).

This consequentialist conception allows obstacles to publicization to be identified, such as the degree to which public liberties are achieved: people's ability to aggregate, develop self-consciousness and acknowledge common interests; the belief that consequences are controllable and not inevitable; and the ability to relate a cause to an effect. We thus paid attention to situated risk conceptualization, which lay beyond objectivation of material impacts of eutrophication on coastal people, but also beyond the cultural theory of risk (Douglas and Wildavsky 1983) that authors of our corpus preferentially engage with when describing eutrophication-related local conflicts (e.g., Hänninen 1992; Kim 2003). To this end, we follow Eugene Rosa's definition of risk as an ordeal, a "situation or event where something of human value (including humans themselves) has been put at stake and where the outcome is uncertain" (1998: 28). This definition avoids assuming cultural determinism in a world in which ecological concerns and concepts tend to circulate and rapidly reshape situated conceptualizations of mutual humanenvironment threats. In this perspective, risks involved in confronting eutrophication phenomena appear "as a cognitive frame that produces contexts which link an object of risk (a source of potential harm), an object at risk (a potential target of harm) and an evaluation (implicit or explicit) of human consequences" (Boholm 2003: 175).

From these various hydro-social assemblages are derived contrasting visibilities of coastal eutrophication phenomena: forms of regulation, materiality of eutrophication symptoms, social representations of water cycles and land-sea interactions, conceptions and uneven exposure to risk. As Rutgerd Boelens (2015) noted in his study of water regulation in the Andes, eutrophication participates in unstable hydro-social configurations that defy the ideal and largely imagined spatial and temporal congruence of hydrological and social territories and the dream of encapsulating human, nonhuman and institutional networks pursued in water management. Indeed, hydro-social configurations are evolving rapidly, and thinking in terms of unstable "configurations" helps capture the heterogeneity of such assemblages. With this configurational approach, we looked for commonalities among the scattered hydro-social territories, which are conceived as "spatial configurations of people, institutions, water flows, hydraulic technology and the biophysical environment that revolve around the control of water" (Boelens et al. 2016: 1 ), in our study's landscape. We expand on these results in the final section, in which we develop a typology of hydro-social configurations associated with nutrient-based pollution that overfertilizes coastal ecosystems. 


\title{
Toward Evidence of Successive Hydro-social Cycles Associated with Coastal Eutrophication
}

In this section, we build on cases intensively studied by qualitative social research using a diachronic approach. We define ages of eutrophication, provide evidence of successive cycles associated with specific framing activities embedded in socio-technical dominant systems, and show how these cycles only recently achieved the status of global nutrient-based ocean pollution.

\section{Early Local Warnings in Coastal-Urban Environments: A Patchy Landscape}

In 1905, the British Board of Agriculture and Fisheries commissioned two preeminent biologists (Letts and Richards) to investigate the prodigious growth of Ulva lactuca var. latissima in Belfast Lough (Northern Ireland). Within 10 years, large blades of this species of green algae had replaced Zostera marina seagrass beds and covered the entire mudflat at low tide. As the French phycologist Camille Sauvageau (1920: 124) reported at the time:

\begin{abstract}
Experiments and analysis by Letts and Richards showed that Ulva latissima had an extraordinary ability to absorb ammonia and nitrates dissolved in the water, and the nitrogen it holds corresponds to the degree of pollution of the water ... Its role remains very positive as long as it grows attached to the substrate ... But at the end of summer and at fall, a large number of them ... go free and are taken by the current. Some of them drop off in depressions on the muddy flat, moving with each tide. However, most are stranded on the shore and accumulate ...; algae soon putrefy, especially when the temperature is high, spreading a pestilential smell; sometimes so much hydrogen sulfide is emitted that the white paint on boats and houses blackens in a single day ... Local residents made sure to complain to public authorities.
\end{abstract}

Odors, headaches, and worries about degradation of houses and boats from hydrogen sulfide emissions eventually played a role in such complaints, but so did depreciation of properties of residents along the lough (Chevassus-au-Louis et al. 2012).

Among marine biologists, Belfast Lough is a well-known, and possibly the earliest, case of early eutrophication due to massive nutrient inputs in a semi-enclosed coastal area. These precious accounts were rediscovered in the 1990s and 2000s, as coastal eutrophication was spreading on multiple shores and causing macroalgal blooms. In the context of endless controversies about the role of nitrogen as a factor limiting algal growth in marine environments and on hydrogen sulfide's threats to human health and well-being, the report of Letts and Richards demonstrated that mechanisms of coastal eutrophication and their consequences on local people had already been acknowledged nearly a century earlier (Ménesguen 2018). The report eventually acquired the value of an early warning.

Twenty years later, and a few thousand kilometers to the east, Finland experienced its first environmental mobilizations in Helsinki (Hänninen 1992). The water supply and sewer systems had reached a certain level of performance for the era, with direct effect that had decreased mortality from typhus and cholera. Nonetheless, like in other urban areas in early industrialized Northern and Western countries, sewers led to the nearest shoreline, which was also used for leisure purposes. In 1929, Helsinki residents started to protest, demanding that sewer drains be moved so that they could bathe and relax on a clean shoreline. This mobilization relied on one major argument: inequalities that affected recreational activities and the quality of life in Helsinki, since the pollution concentrated near popular shorelines of the low-income districts. Letts and Richards attributed the eutrophic crisis in Belfast Lough to a failure of sewer systems, 
caused by rapid demographic growth and industrial development upstream, which were the same conditions in Finland in the 1920s. Vegard Arnesen (2001) provides a similar account for the urban area of Oslo, Norway, during the same period. The "first age" of anthropogenic coastal eutrophication emerges from these examples: direct discharge of industrial waste and sewage were identified as the main sources of nutrient pollution.

Currently, few accounts of this initial age are available. In the cases described, early ecological science was central at the time for managing eutrophication itself; currently, ecological science is a reliable and detailed source of environmental history of eutrophication. Nonetheless, because of the focus on biotechnical data, we still have little information about social mobilizations, experiences of eutrophication and impacts on local people, who appear accidentally as depersonalized alerts or complaint operators. Few traces of the main concerns that lead to research efforts on these topics before 1940 are available, and it is difficult to know whether, how, or why people raised their voices. Besides the Helsinki event, Sakari Hänninen (1992) found no trace of environmental mobilization before the 1980s, which highlights the nonlinearity and noncumulative nature of the raising of environmental concerns and the volatility of their focus. It also shows that public operators were able to achieve appropriate action and that, in a way, local solutions to local problems were at least partially performative during the initial age. This patchy knowledge leaves many questions unanswered. Does the lack of documentation and research have something to do with the low social visibility of environmental change (i.e., little social awareness and concern despite the physical materialization of the problem)? Or were no social scientists available to capture the phenomenon?

\section{Social Visibility of Coastal Eutrophication: From Perceptions to Frames}

Under what conditions can environmental changes be noticed and interpreted as anomalies, irregularities, or an issue for society? As affected territories expanded and their local problematization evolved and diverged from the 1960s to the end of the twentieth century, this became a crucial question for scholars to address what we call the "second age." The degree to which the intensity and nature of biophysical symptoms influence these experiences or perceptions remains disputed. Indeed, conceptualizing the relationship among the social visibility of coastal eutrophication, the materiality of these changes, and the trajectory of affected socio-ecosystems is complex. Manifestations (or symptoms) of coastal eutrophication are heterogeneous, some being visible (e.g., colored microalgal blooms, massive fish mortality) and some not (e.g., partial or total oxygen depletion-hypoxia or anoxia-with no visible bloom or smell in turbid waters), while potentially causing acute toxicity. Such heterogeneity is also related to the biophysical characteristics of coastal socio-ecosystems vulnerable to

Figure 1: Microalgal bloom in the Baltic Sea (Medium Resolution Imaging Spectrometer image) on 13 July 2005 (@ European Spatial Agency). Reprinted with permission under CC BY-SA 3.0 IGO.

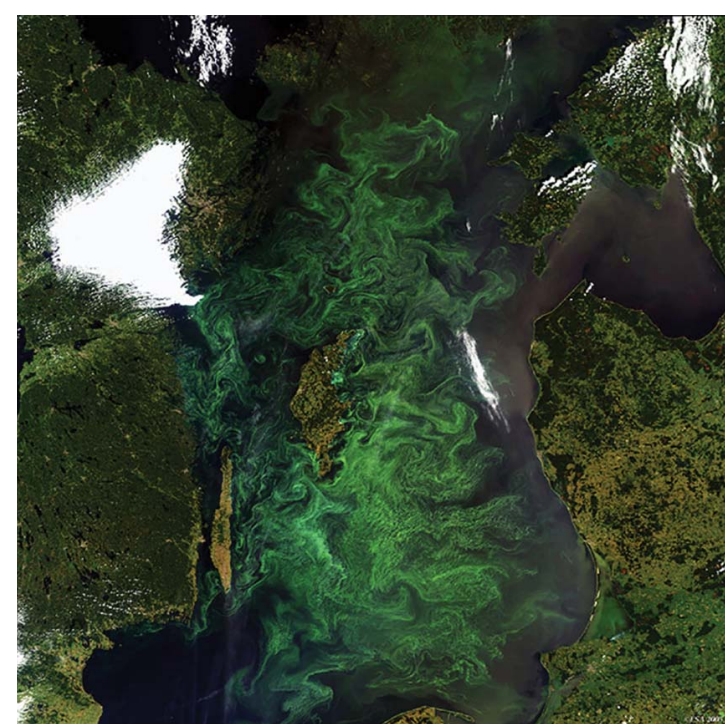


eutrophication symptoms (e.g., semienclosed bays, larger gulfs, estuaries, coastal lagoons) and associated with a wide range of uses.

Seminal works in environmental psychology in the 1970s and 1980s dealt with layperson judgments of water quality, with the main evaluation criteria being water clarity and the nature of submerged vegetation. However, further studies emphasized that assessment of water quality depends on expectations for the surrounding landscape, and that perceptions are contextualized judgments embedded in "perceptual sets" (Isaacson and Blum 1967; Moser et al. 2004). Since the distance between most people and "natural" aquatic systems tends to grow with industrialization, perceptions tend to be oriented toward specific uses and experiences; for instance, there is a disconnect between drinking water, swimming water, and other types of water. As Amy Freitag (2014) showed after conducting fieldwork in the Chesapeake Bay, the very idea of water quality varies depending on ways of knowing associated with the specific relationship to the ecosystem, resulting in the coexistence of two main visions of water quality in fishing communities, which are also encapsulated in public policies. For instance, the Clean Water Act in the United States holds both visions by

Figure 3: A boy meeting stranded algae from a "green tide" in Brittany, France, in 2010 (๔ Alix Levain).

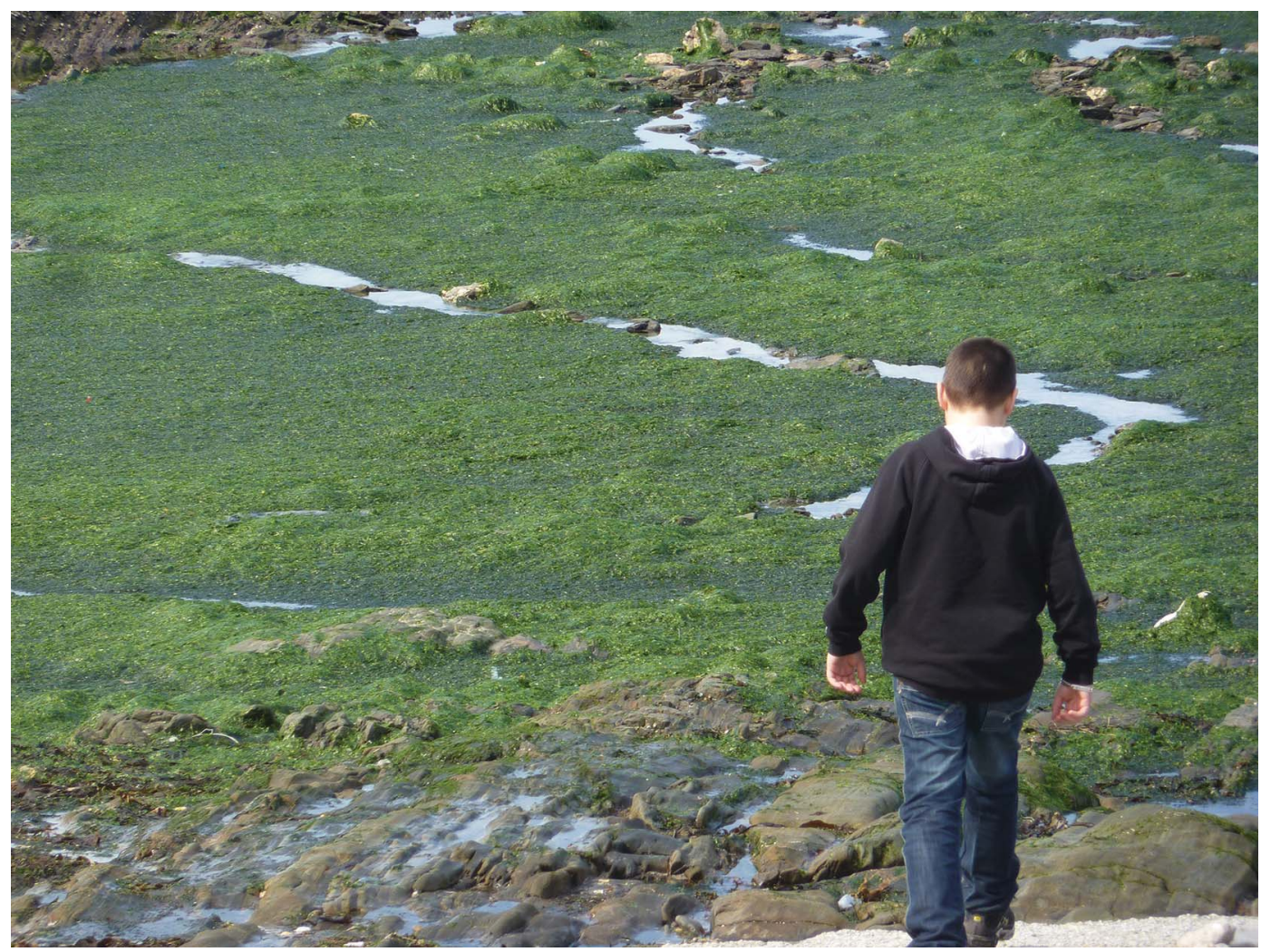


defining water quality by both biochemical parameters and water's suitability for swimming and drinking.

In coastal waters, this suitability is associated mainly with recreational activities, fishing, and harvesting of marine resources. Although obvious, this reality is full of consequences, since it restricts and orients the acquisition of social visibility. In this regard, Kenneth Gould, who studied social movements fighting pollution in the Great Lakes of North America, made a useful distinction between primary and secondary visibility. Primary visibility engages a direct relationship with surrounding natural objects and systems since it reflects the "extent to which a particular environmental problem is readily detectable through first hand observation of the phenomenon." Secondary visibility stresses that social visibility is embedded in social interactions: "increased access to certain information makes an environmental problem more socially visible, in a secondary sense, by allowing people to recognize either the existence or impacts of particular environmental threats" (1993: 158). As one may surmise, neither type of visibility is "pure" or mutually exclusive as long as social segmentation and unequal distribution of social resources are addressed. In Belfast Lough, for instance, complaints seem to have been triggered by primary visibility of eutrophication symptoms (e.g., algal blooms and odors), and to be untargeted.

In contrast, Helsinki appears to be a case of secondary visibility, because of the existence of mediations: people knew about the sewer system failure, and built a cause into a set of arguments that included water quality, in a typical reversal scenario between the solution and the problem that Joseph Gusfield (1984) conceptualized in his seminal book on the construction of public problems. Significant press coverage allowed a historian like Hänninen to find sources of information to rely on. The mobilization was also caused by the existence of organized social movements for access to recreational activities and a reduction in working hours. In addition, pioneer scientific research on phytoplankton in the Baltic Sea had been performed for more than 50 years (Finni et al. 2001). We do not know, however, what form(s) the eutrophication phenomena took in Helsinki's bay. Gould's distinction thus helps identify why the same phenomena may increase in visibility over time or become the subject of unequal perceptions due to uneven distribution of social resources (e.g., material, organizational, relational, informational).

\section{Questioning the Secondary Visibility of Coastal Eutrophication during the "Second Age"}

One of the first oceanic symptoms to be related to anthropogenic eutrophication during the "initial age"-massive blooms of benthic macroalgae (e.g., "green tides," "brown tides")—are also one of the most common and visible. Although limited to a few cases, green tides are one of the most intensively studied symptoms in our corpus. Consequently, green tides have a priori high primary social visibility: they provide a preferential viewpoint from which to understand the degree to which social and cultural norms and practices contribute to frame the sensitive relationship with the environment. Familiarity with chronic green algae blooms has sometimes lasted for decades for coastal communities, such as in the Chesapeake Bay (US), Peel Inlet (Australia), the Tunis lagoon (Tunisia), the Galician rías and delta of the Ebro River (Spain), the Venetian Lagoon and Adriatic coast (Italy), and the Arcachon basin and the coasts of Brittany (France) (Morand 2005).

As long as an environmental change avoids any kind of narrative, few people may notice and have access to this "reality." This prerequisite illuminates the transition from primary to secondary visibility but also provides opportunities for refining features and patterns of the hydro-social cycle in the "second age," especially the complex relationships among environmental change, knowledge production, and uncertainty. An ethnography of green tides in Brittany, France, performed from 2010 to 2014 (Levain 2014) provides evidence of this complex 
coexistence (Figure 2 and Figure 3). Green tides have occurred in the most severely affected coastal areas of Brittany since the 1970s, after a lag time that corresponded to the response time of coastal watersheds to massive changes in nitrogen fertilization and landscape structures associated with the Green Revolution. Testimonies of older coastal residents, rooted in their fishing and bathing experiences during childhood, often confirm the scarce information from public archives that the area has indeed experienced green tides, despite the relative lack of press coverage and public interest at the time. They also emphasized their lack of surprise at a phenomenon that they considered natural: they understood the appearance of algal blooms in a semi-enclosed aquatic body to be similar to what they observed in ponds or water troughs, and the magnitude of the phenomenon appeared to be consistent with the degree of transformation of rural landscapes and intensification of farming practices they faced.

In the 1980s, however, social visibility of green tides increased as coastal communities relied increasingly on tourism, and conflicts emerged from continuous expansion of livestock farms. An instrumental condition for this change was the development of research programs that assessed the direct relationship between local farming intensification and algal growth. In this context, local farmers tended to include intimate knowledge and daily experience of coastal waters into their struggle to legitimize farming practices. As a result, rural coastal communities tended to polarize over the long term, and discourses about green tides tended to separate into a narrative/counter-narrative structure, to the point that individual assessments of the evolution of the magnitude of green tides was shaped by the individual's proximity to the agricultural social world (Le Chêne 2012). New residents were sure that the situation was worsening, while others asserted it was clearly improving, which influenced over the long term the legitimacy and credibility of local knowledge about how to manage eutrophication.

Perceptions are not straightforward: the visibility of an issue is mediated by many social factors, and resources are needed to expand social visibility. Here, we arrive at the core of social complexity. On the one hand, empirical data on green tides shows that traumatic historical events influence cultural tipping points (i.e., long-term transformations of social representations). On the other hand, these tipping points are involved in competing narratives. In Brittany, one such event was the first set of "black tides" on the English Channel and Atlantic shores due to crude oil spills: the Torrey Canyon in 1967 and the Amoco Cadiz in 1978. Massive symptoms of coastal eutrophication appeared in northern Brittany three years after the Torrey Canyon spill, and the idea that the two events were connected never disappeared locally. For those who attempted to minimize, delay, or deny the agricultural origin of green algae proliferation, this idea made it possible to downplay green tides as a side event, direct consequence of, or lesser evil than this catastrophe. At the same time, green tides seemed like an unacceptable and endless repetition of this traumatic event, feeding contemporary denunciations of and layperson inquiries into its damage to human and nonhuman life, thus contributing to the emergence of new frames and critical readings, such as the spectra of biotic homogenization, the disappearance of natural and nurturing forms of marine life, the intrinsic dangerousness of algae to health, and the symmetric predatory behavior of pigs and algae for vulnerable human and nonhuman beings (Levain 2013) (Figure 4).

Figure 4: Dogs drooling green algae. Plastic figures by Xavier Théffo (2010) (๔ Xavier Théffo). Reprinted with permission.

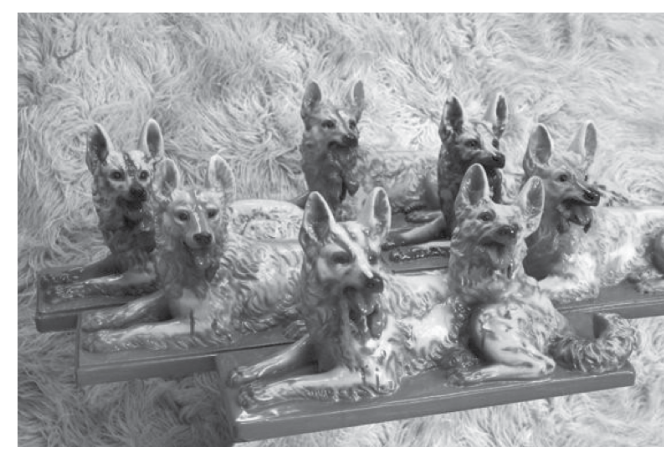


The case of green tides in the Bay of Qingdao (Shandong, China) illustrates how contrasting, and even segmented, social visibilities may coexist and how much they depend on the observer's reference point. For instance, vendors collect sea lettuce (U. lactuca and similar species), the algae involved in most European green tides, wash $U$. prolifera fragments off them and sell them as seafood on the seaside in the urban area of Qingdao (Figure 5). Many $U$. prolifera (known locally as hǔ tái) blooms have occurred in Qingdao since the first major bloom during the 2008 Summer Olympics. Each time, they arouse the international medias' interest and give rise to stunning pictures of this presumably blue flowing ocean, turned into a huge bright green wet meadow, where people bathe and play with unspoiled pleasure. They are often associated with comments about how Chinese people are different and live in a world apart-a world where, somehow, ecological collapse has already occurred. However, an ethnographic study completed in 2011 indicated that Qingdao residents refuse to bathe in that hu tai soup, unlike tourists from rural China, most of whom are taking their one and only seaside vacation, which they have dreamt about for years. In addition, there are hard feelings about hu tai locally, but no ability to criticize it in the public arena, except to express anger at international media coverage of the problem (Levain 2017).

In many cases, the magnitude of the damage is not clearly correlated with the perception of an environmental distortion or with the intensity of mobilizations, since interpretive tensions lie at the core of local conflicts and mobilizations. This also explains why the situation, nurtured by the segmentation of social worlds and political time, tends to remain in a liminal state. While green tides, red tides, and hypoxia tended to spread and accentuate from the 1970s to 1990 s, this liminal state may explain why coastal eutrophication remained discreet during this period: addressing it would have been challenging, since no shared social interpretation or prevalent political frame had yet emerged. It is a conflictual and nonlinear process. One way to understand this receding horizon and how it is experienced is to look at the framing activities of institutional actors (i.e., how they construct meanings through frames of understanding of a situation and make it "natural" (Gusfield 1984)). Intensive interdisciplinary research conducted around the Baltic Sea offers a perspective for reflection. Building on historical empirical data in Sweden, Marianne Löwgren et al. (1989) demonstrated the relevance of understanding eutrophication management as a whole (i.e., paying attention to both freshwater and coastal management). They showed the degree to which strategies to decrease nutrient pollution throughout the twentieth century were driven by successive frames that, until recently, excluded the ocean.

Indeed, in most documented cases, management of nutrient pollution was first dominated by health concerns and focused on specific areas and sensitive points (e.g., water supply sources and watersheds) and only rarely on strategic relocation or extension of wastewater discharge to lakes or seashores. Management strategies were concerned mainly with protecting human health and fisheries (Laakkonen and Laurila 2007). In addition, since water pollution management was governed by social perception of the feasibility and practicability of solutions, abatement strategies focused on biotechnical control of the water cycle. This kind of socio-technical system leaves the ocean separate, as an unmanageable place, until more holistic conceptual- 
izations of water pollution emerge: "During the last 50 years temporal and spatial scales have been widened. Measures taken did not correspond to current conceptualizations of water pollution. Considerable lags of implementation were found and technical solutions accumulated into infrastructural networks of an increasing magnitude and complexity" (Löwgren et al. 1989: 161).

The prevalence and stability of biotechnically oriented frames characterizes the second age of coastal eutrophication in industrialized countries until at least the 1990s. After this period, maintaining these frames required increasing effort from their supporters because of the challenges of open and complex coastal systems, which prevented notable improvement for long periods. In addition, coastal eutrophication began to increase in scale, due to the Green Revolution and the expansion of the agrochemical industry, which actively changed the cultural relationship with maintenance of public and private gardens and lawns (Robbins et al. 2014; Whitney 2010). Consequently, the cumulative effects of nutrient runoff tended to affect large, urban, coastal areas in industrialized countries.

During this period, eutrophication became one of the environmental issues for which the influence and engagement of ecologists in public debates was the most significant and effective (De Jong 2016; Nelkin 1976; Schneider 2000). Ecologists helped sharpen research and were, from the beginning, deeply connected to local struggles. The attention of these social actors and their cognitive equipment was key to the emergence of eutrophication as a public issue in the United States, Canada, and Northern Europe in the 1970s, which in return helped professionalize and shape ecology as a scientific community (Nelkin 1976). Eutrophication thus became an explicit subject of public policies, and the literature provides several detailed accounts of how it became part of the political agenda at the time (Feldman et al. 2000; Francis 1988; Kehoe 1992). This was the case, for instance, of the Rimini resort on the Adriatic coast (Italy) where local representatives worked to identify similar problems in Europe and recognized that coastal eutrophication issues throughout Europe threatened the development of tourism (Becheri 1991). Only a few active coastal fronts-the Chesapeake Bay and Northern Europe-experienced visible public concern and activism. In Baltic countries, for instance, marine eutrophication was a major topic of press coverage during this period (Jönsson 2011; Lyytimäki 2012).

As symptoms of eutrophication spread, scientific communities expanded around them, and their focus tended to change from freshwater limnology to more integrated and systemic approaches to aquatic systems, progressively considering the systems' degrees of openness and complexity (Cloern 2001; Eloffson et al. 2003). Indeed, coastal eutrophication became one of the most studied topics in ecology in the 1980s and 1990s (Nixon 2009). These decades were marked by "the N/P controversy" (De Jong 2006): since research had demonstrated the leading role of phosphorus inputs in eutrophication of freshwater lakes and reservoirs, which led to calls for legislation to ban phosphate in detergents, marine biologists struggled to assert their view of eutrophication driven by nitrogen inputs in marine environments. Indeed, the agenda setting was oriented toward phosphate as a lever of action at the time (Bourblanc 2019). Moreover, the volatility and solubility of nitrogen compounds and the wide distribution of their sources made them poor candidates for effective short- and mid-term public action.

These scientific controversies are entangled in complex science-policy interactions, in which research has long been polarized and pressured, first by industrial farming and fertilizers manufacturers' interests, but also by public authorities. Indeed, persistent gaps between and conflicts over target values and achievements span the century-long history of fighting eutrophication. However, most accounts stress a simple fact: management of point-source pollution has improved, due to more stringent regulation of and technical progress in wastewater management (for a retrospective and reflexive history of the Patuxent River's contribution to Chesapeake Bay nutrient pollution from 1960 to 2000, see D'Elia et al. 2003). The underlying 
political dimension of these improvements is that public institutions can negotiate directly with organized, identifiable parties. Sometimes, other public authorities manage water infrastructure, which may ease negotiations. This improvement obviously does not mean that the process did not take time or struggle, or that policies cannot be criticized.

This narrative contrasts with the major problem and management dilemma identified by authors in political science, institutional economy, and environmental sociology: nonpoint-source pollution has not been handled as well and, on the contrary, has increased, in part because of active industrial, urban, and rural development policies (e.g., incentives to use fertilizers in the US; Whitney 2010). In this context, local experiences of eutrophication extend over a long period, and the receding horizon of public policies up to the present, even when they pursue ambitious goals, influences both the legitimacy of the public officials who personify them and the scientific knowledge on which the policies are-or claim to be-based. This frail basis for transformative action echoes marine eutrophication's characterization as a wicked issue and leaves room for competing interpretations and controversies: this issue, so well known and described because of intense and long-term consensus building within scientific communities, still requires problem definition and contextualized redefinition (Bourblanc 2019; Linke et al. 2014). To take an anthropologist's typical empirical indicator, how people talk locally about green tides in Brittany highlights this "wicked" dimension: whether in the intimacy of interviews, in the often subversive and ferocious humor of bar talk, or in artistic expression, algal biomass exists as an excremental, obscene, and out-of-place "problem," a "mess" difficult to grasp and name precisely, beyond its disturbing nature (Levain 2014). Indeed, dealing with coastal eutrophication for a long time generates a focus on both signs and alternative explanations and etiologies, accentuated by the need to objectify problems and find out whom to blame them on.

As observed in Brittany, the North Sea (De Jong 2016), the Baltic Sea (Ulén and Weyhenmeyer 2007), and the Chesapeake Bay (Paolisso et al. 2015), the accumulation of scientific accounts and public knowledge leads only to demands for more accountable knowledge. Meanwhile, the complexity of marine responses and associated large uncertainties permanently challenge scientific legitimacy. Likewise, local public policies struggle to document improvements, despite the emergence of science-policy coordination plans such as the EU Water Framework Directive, which recognizes coastal waterbodies as part of water systems governance (Kitsiou and Karydis 2011). The ability to obtain visible results by regulating nutrient inputs is regularly questioned. Works analyzing the 1960s-2000s period that we call the second age ultimately help acknowledge the limits of historicizing and the need to pay close attention to the intensity of conflicts, situated knowledge policies and competing framing activities that surround the interpretive work and experience of social actors. However, these dimensions of coastal eutrophication's socialization remain only partially and unevenly documented, and evolve rapidly.

\section{Transition to a Third Age? Conditions of Emergence of Eutrophication as a Global Problem}

The upscaling of coastal and marine eutrophication problems, characteristic of the transition between the second and third ages, is due to simultaneous changes in the materiality, areas of concern, advocacy, and assessment of coastal eutrophication. The 2000 s were marked by major inputs from life-science research and expertise, which led to signs that coastal eutrophication would be recognized as a global environmental problem because of coordinated research efforts that implicitly denounced the inefficiency of local management. The first sign was an effort by major international programs such as the Intergovernmental Panel on Climate Change to unify and describe the history of local observations of coastal eutrophication phenomena. As 
a result, the first international inventory of eutrophicated coastal zones was published in 2008, identifying 764 severely affected coastal areas and 177 dead zones (Diaz and Rosenberg 2008). The second sign was the emergence of new scientific frameworks that assessed relationships between nitrogen and phosphorus inputs at the global scale and the worldwide expansion of eutrophication and anoxic events, thus helping make coastal eutrophication a global environmental problem. A key moment of assessment and articulation of multiple environmental changes attributed to human influence was the Millennium Ecosystem Assessment (2005), which itemized and performed meta-analysis of threats at a global scale.

High levels of nutrient loading were considered a major water pollution issue, with harmful effects on populations. Assessment of "planetary boundaries" (i.e., sustainability limits of the terrestrial ecosystem), led by environmental scientists of the Resilience Alliance, considered disruption of the biogeochemical nitrogen cycle as the most serious and irreversible global threat, far worse than disruption of the carbon cycle (Rockström et al. 2009; Steffen et al. 2015). The team used two indicators of marine eutrophication to estimate this boundary and the degree to which it had been crossed. Formalization of coastal eutrophication as a global environmental problem thus closely followed the emergence of global environmental discourse at the beginning of the 2000s (Adger et al. 2001). These boundary works are indeed supported by major unprecedented eutrophic events that raised the specter of large-scale and irreversible death of marine environments, such as in the Gulf of Mexico or the Baltic Sea. These eutrophic events show the complexity of ocean disruptions by anthropogenic nutrient inputs and generate new perspectives in ocean research, emphasizing the risk for global oceanic deoxygenation (Breitburg et al. 2018; Levin 2018; Paerl et al. 2018).

\section{Hydro-social Assemblages during the "Third Age"}

As shown in the first section, our literature review indicates that these global trends contribute to the recent development of interdisciplinary publications involving social scientists. Nonetheless, social science publications that address the magnitude of these changes remain rare. In particular, large areas remain ignored, and analysis of connections between local and global material and immaterial flows can be strengthened by fostering dialogue between critical approaches and empirical case studies. For now, the effects of such changes in the magnitude and global framing of coastal eutrophication are indeed difficult to assess. This "third age" eventually increases risks to coastal residents and communities, especially vulnerable people "at the end of the pipe." At the same time, older fronts of coastal eutrophication remain active. Following our diachronic and multisite analysis and attempt to connect it to this change, we perform a transversal reading of recent case studies that address social mobilizations and conflicts related (in one way or another) to coastal eutrophication.

Our typology of hydro-social configurations builds on Gould's (1993) aforementioned distinction between primary and secondary visibility, which proposes a way to integrate ecological and social dimensions that shape local perceptions and problematization of nutrient pollution. It allows the uneven distribution of costs and benefits of eutrophication phenomena themselves to be addressed and to be related to the public policies fighting them at the local scale. Indeed, political science has shown that decision-makers constantly negotiate policy objectives and dedicated policy instruments while considering the social groups impacted, the type of public issues at stake, and the sector targeted. We strengthen the political dimension, however, by extending this approach in two directions: first, by introducing a multi-scale perspective based on our diachronic analysis, and second, by examining the science-policy interface with a political ecology perspective. 
The resulting typology is organized into three sets of criteria. The first set, which addresses primary visibility, relates to the nature and intensity of pollution symptoms and to the ability to connect their origins, forms, and consequences through local observation. The second set, which addresses secondary social visibility, combines descriptions of the social position and vulnerability of affected social groups with framings attached to pollution, local disputes, and socio-technical controversies. The third set is composed of three criteria that describe governance and regulation regimes: the type of regulation within targeted sectors, the type of science-policy interactions and epistemic cultures, and the associated regulation dynamics and scale strategies. Our analysis yielded four configurations, which we describe next and summarize in Table 1, that provide a heuristic, initial overview, but one that is still worth refining, since

Table 1: Summary of Hydro-social Configurations Related to Coastal Eutrophication

\begin{tabular}{|c|c|c|c|c|}
\hline $\begin{array}{l}\text { Hydro-social } \\
\text { configuration/ } \\
\text { criteria }\end{array}$ & $\begin{array}{l}\text { Type } 1 \\
\text { Noisy eutro- } \\
\text { phication in } \\
\text { eco-frontiers }\end{array}$ & $\begin{array}{l}\text { Type } 2 \\
\text { Overwhelming } \\
\text { dystrophic } \\
\text { disruptions }\end{array}$ & $\begin{array}{l}\text { Type } 3 \\
\text { Silenced } \\
\text { eutrophication }\end{array}$ & $\begin{array}{l}\text { Type } 4 \\
\text { Disturbing } \\
\text { eutrophication }\end{array}$ \\
\hline $\begin{array}{l}\text { 1. Primary } \\
\text { visibility/salience }\end{array}$ & Segmented & High & $\begin{array}{l}\text { Variable } \\
\text { Prevalence of other } \\
\text { visible/damaging } \\
\text { pollution }\end{array}$ & Variable \\
\hline $\begin{array}{l}\text { Intensity and nature } \\
\text { of pollution/ } \\
\text { eutrophic events }\end{array}$ & High intensity & $\begin{array}{l}\text { High intensity } \\
\text { Recurring harmful } \\
\text { microalgal blooms }\end{array}$ & High intensity & Variable \\
\hline Scale of the problem & $\begin{array}{l}\text { Local scale } \\
\text { Nonpoint-source } \\
\text { nutrient pollution }\end{array}$ & $\begin{array}{l}\text { Global scale } \\
\text { Rarely identifiable }\end{array}$ & $\begin{array}{l}\text { Local scale } \\
\text { Point-source } \\
\text { nutrient pollution } \\
\text { Extraction } \\
\text { industries, } \\
\text { urbanization, } \\
\text { artificialization }\end{array}$ & $\begin{array}{l}\text { Local scale } \\
\text { Nonpoint- } \\
\text { source nutrient } \\
\text { pollution } \\
\text { Intensive } \\
\text { farming } \\
\text { Aquaculture }\end{array}$ \\
\hline $\begin{array}{l}\text { 2. Secondary } \\
\text { visibility }\end{array}$ & High & Low & Low & Growing \\
\hline $\begin{array}{l}\text { Nature of hazards } \\
\text { (types of public } \\
\text { issues: environmen- } \\
\text { tal, health, aesthetic, } \\
\text { moral, etc.) }\end{array}$ & $\begin{array}{l}\text { Moral } \\
\text { Aesthetic } \\
\text { (alteration of } \\
\text { landscapes) } \\
\text { Environmental }\end{array}$ & $\begin{array}{l}\text { Human health } \\
\text { Economic } \\
\text { Environmental }\end{array}$ & Poorly documented & Economic \\
\hline $\begin{array}{l}\text { Social position and } \\
\text { mobilization } \\
\text { capacity of affected } \\
\text { social groups }\end{array}$ & $\begin{array}{l}\text { Low vulnerability } \\
\text { Recreational } \\
\text { activities } \\
\text { Professional and } \\
\text { leisure fishing } \\
\end{array}$ & $\begin{array}{l}\text { High vulnerability } \\
\text { Fishing, } \\
\text { shellfish } \\
\text { harvesting, } \\
\text { aquaculture }\end{array}$ & $\begin{array}{l}\text { Poorly documented } \\
\text { Fishing, shell- } \\
\text { fish harvesting, } \\
\text { aquaculture }\end{array}$ & Heterogeneous \\
\hline $\begin{array}{l}\text { Local disputes and } \\
\text { socio-technical } \\
\text { controversies }\end{array}$ & $\begin{array}{l}\text { Highly visible; } \\
\text { structuring and } \\
\text { regulated conflicts }\end{array}$ & Rarely detectable & Rarely detectable & $\begin{array}{l}\text { Irregular } \\
\text { Poorly regulated }\end{array}$ \\
\hline $\begin{array}{l}\text { Framings attached } \\
\text { to pollution }\end{array}$ & Targeted & Untargeted & Untargeted & Disputed \\
\hline
\end{tabular}


Table 1: Summary of Hydro-social Configurations Related to Coastal Eutrophication (continued)

\begin{tabular}{|l|l|l|l|l|}
\hline $\begin{array}{l}\text { Hydro-social } \\
\text { configuration/ } \\
\text { criteria }\end{array}$ & $\begin{array}{l}\text { Type 1 } \\
\text { Noisy eutro- } \\
\text { phication in } \\
\text { eco-frontiers }\end{array}$ & $\begin{array}{l}\text { Type 2 } \\
\text { Overwhelming } \\
\text { dystrophic } \\
\text { disruptions }\end{array}$ & $\begin{array}{l}\text { Type 3 } \\
\text { Silenced } \\
\text { eutrophication }\end{array}$ & $\begin{array}{l}\text { Type 4 } \\
\text { Disturbing } \\
\text { eutrophication }\end{array}$ \\
\hline $\begin{array}{l}\text { 3. Regulation } \\
\text { dynamics }\end{array}$ & Strong & Weak & Weak & Strong \\
\hline $\begin{array}{l}\text { Type of regulation } \\
\text { within the sector tar- } \\
\text { geted: policy instru- } \\
\text { ments used, degree } \\
\text { of inclusiveness of } \\
\text { policy decision }\end{array}$ & $\begin{array}{l}\text { Integrated, } \\
\text { high degree of } \\
\text { complexity }\end{array}$ & $\begin{array}{l}\text { Regulation of access } \\
\text { to marine resources } \\
\text { harvesting, } \\
\text { fishing); } \\
\text { commercial barriers }\end{array}$ & $\begin{array}{l}\text { None, except if } \\
\text { international } \\
\text { protection status }\end{array}$ & Unsteady \\
\hline $\begin{array}{l}\text { Type of science- } \\
\text { policy interactions } \\
\text { and epistemic } \\
\text { cultures (e.g., } \\
\text { degree of openness } \\
\text { of public debate) }\end{array}$ & $\begin{array}{l}\text { Systematic with } \\
\text { a strong } \\
\text { interdisciplinary } \\
\text { component }\end{array}$ & $\begin{array}{l}\text { Limited to } \\
\text { health-related issues }\end{array}$ & $\begin{array}{l}\text { Highly conflictual } \\
\text { and/or dominated } \\
\text { by engineering }\end{array}$ & $\begin{array}{l}\text { Segmented, } \\
\text { dominated by } \\
\text { biophysical } \\
\text { knowledge }\end{array}$ \\
\hline $\begin{array}{l}\text { Dominant regulation } \\
\text { scales }\end{array}$ & $\begin{array}{l}\text { Multi-scale and } \\
\text { integrated } \\
\text { (international- } \\
\text { regional-local) }\end{array}$ & Local & International-local & Regional-local \\
\hline
\end{tabular}

the few case studies does not reflect the magnitude of the issue. In addition, the typology must be integrated in a dynamic approach in order to consider potentially rapid social and institutional change.

\section{"Noisy" Eutrophication: Algae "Shouts" at Eco-frontiers}

In the first configuration, we grouped situations in which coastal eutrophication acquires such a high degree of secondary social visibility, because of the social value of spaces and ecosystems affected, that it becomes a central and explicitly addressed issue in political and social life. This is the case of the Baltic Sea, for instance, but one can also find cases in Japan, in Korea, and around emblematic estuaries and bays (e.g., Kim 2003). In this category, the press covers both events and debates, socio-environmental mobilizations are long-standing, and conflict is high, but regulated, and organized into coalitions that support contrasting visions of the future of human-modified coastal ecosystems (i.e., between development and conservation). This configuration represents most of the research effort on which we built our analysis in the second section.

\section{Overwhelming Eutrophication: Human Drama and Marginality}

This configuration is marked by direct confrontation with consequences of eutrophication (no mediation or attenuation), which threaten the survival of coastal communities that depend on fishing and/or aquaculture, as well as a lack of significant public regulation. In an explicit and 
direct manner, it raises questions about social environmental justice. Few articles addressed this topic, but those that did generally included detailed accounts, mainly by ethnographers and historians (e.g., Bankoff 1999; Levain 2017). Eventually, the primary visibility of eutrophication symptoms becomes high, and coastal communities are either placed in often-authoritarian forms of direct state intervention against the phenomenon or condemned to face it with few resources, which increases their vulnerability. In such a context, local authorities often conceptualize local conflicts as a confrontation between human societies and their environment, while political control over practices and discourses of coastal communities strengthens.

For instance, in Qingdao Bay, regional authorities of Shandong Province mobilized fishermen to block drifting algae with their boats and collect them with their fishing nets, and fishing was forbidden in summer (Levain 2017). In this case, human health was not considered directly, and regulations came from both overfishing and the physical inaccessibility of marine space due to the thickness of floating algae. In most documented cases, however, the main threats to coastal communities come from harmful (i.e., toxic) algal blooms. For instance, red tides in the Philippines cause acute and chronic toxicity episodes, leaving coastal-urban communities with no choice but to expose themselves to short- and long-term risks, due to contaminated shellfish consumption, and selling restrictions and prohibition. As Greg Bankoff (1999: 108) notes:

The effectively unrestrained use of coastal waters in the developing (and developed) world to dump the waste and by-products of industrial societies on the one hand, and the inexorable search for cheaper and cheaper sources of protein to feed burgeoning and increasingly impoverished populations on the other, create the conditions in which red tides flourish and the consumption of shellfish rises.

Such increasing vulnerability is also partially documented in other densely populated areas such as the Gulf of Mexico (Jepson 2007) and the Bay of Bengal (India) (Zinia and Kroeze 2015).

\section{Silent or Silenced? Coastal Eutrophication Erased}

In the third configuration, eutrophication is quite silent or invisible. Problematization and social movements associated with concerns about water quality are difficult to detect and generally remain unknown to international or national observers (e.g., NGOs, press). Currently, such situations are poorly documented. They also share the fact that eutrophication is not presented as a public problem or placed in an official narrative. A relative weakness in natural signals, associated with the mundane nature of the water and landscapes affected, explains why urban and mudflat strands, harbors, and large and turbid estuaries are underrepresented in our analysis, unlike coastal lagoons. The active marginalization of places and water is associated with considering them an accessory for development, directly echoing the literature on neoliberal nature invoked in the first section. In such contexts, keeping social visibility low appears to be an active framing process in which nutrient enrichment of water becomes an additional argument for devaluing ecosystem dynamics and advocating for development projects, with their associated draining, sucking, and filling operations (e.g., the coastal lakes of Tunis; Barthel 2003). Political investment in such operations, along with private-capital funding and artificialization, often accompanies attempts to silence challenging voices, and local conflicts emerge where such attempts fail, as recent examples in South Korea and China show (e.g., Gao and Zhang 2010).

Thus, this configuration makes the entanglement of low primary and low secondary visibilities particularly obvious: for instance, extractive industries that use coastal waters as spillways can be associated with environmental depredation and monopolization of public resources. 
Figure 6: Fishermen landing fish on the shore of Lake Maracaibo (Venezuela) in 2015 (๔ Vitalis NPO). Reprinted with permission.

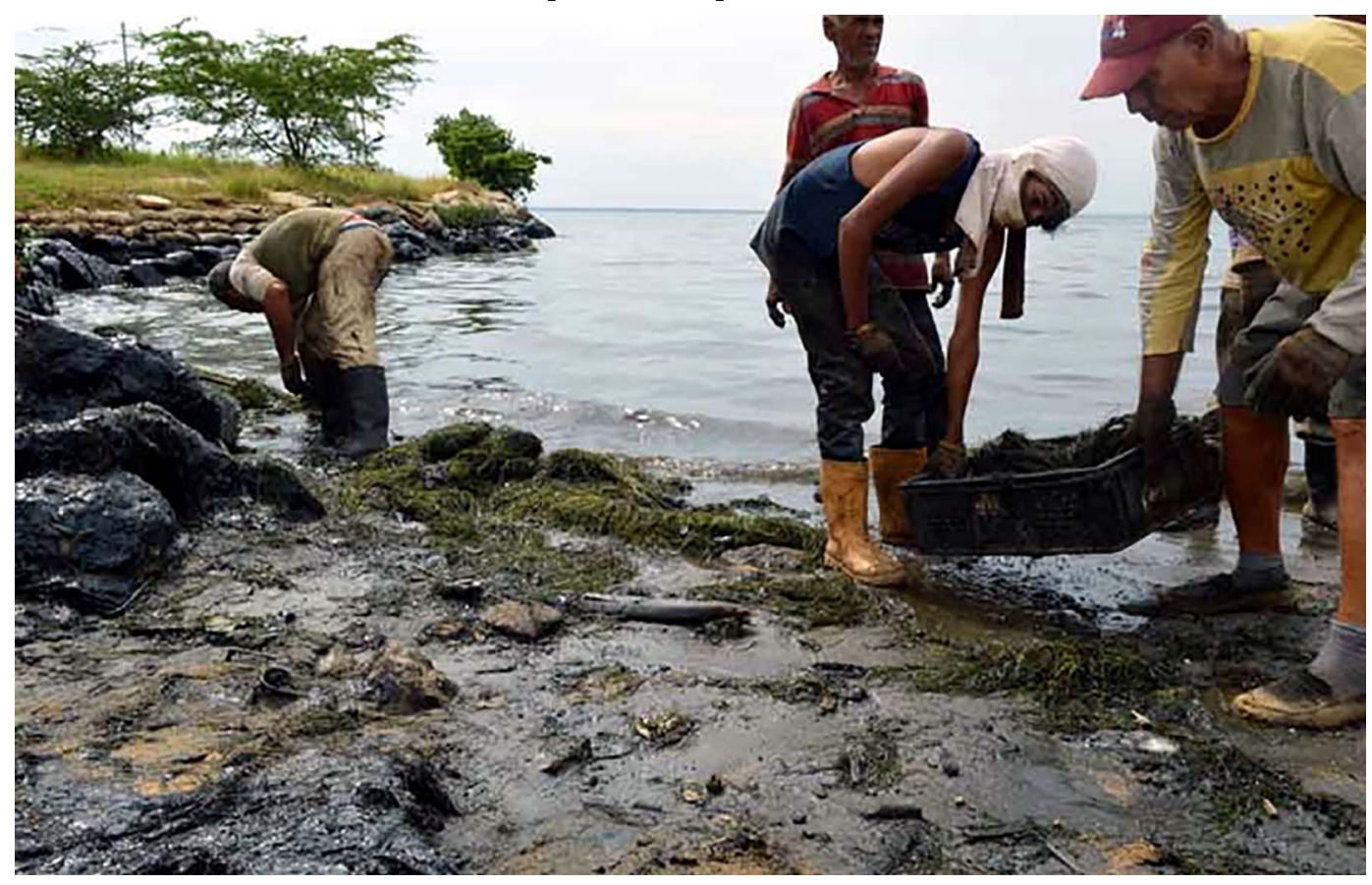

Consequently, water degradation reaches a point at which excessive organic inputs to the aquatic system, even when associated with noticeable and damaging changes, cannot be captured and are lost in global pollution. The coastal lake of Maracaibo, Venezuela, is an example of such a silent configuration (Conde and Rodriguez 1999). Overall, riverine communities that depend on fishing struggle with blue-green microalgal blooms, chronic proliferation of aquatic duckweed (Lemna spp.), and massive oil spills from pipelines and an extractive industrial complex nearby. Fishermen, most from indigenous communities such as the Anu, are the first victims of green-black lake pollution (Figure 6). Despite desperate efforts of local NGOs and concerned scientists from diverse backgrounds, no organized research (whether in ecology or, even less probable, social sciences) or advocacy campaign can be performed in the current political context there, and the only academic sources available on the phenomenon adopt a biotechnical perspective.

\section{Conflict and Disturbing Eutrophication: Trapped in Nonsustainability}

The last configuration is dominated by nonpoint-source pollution, especially from farming. This configuration is now dominant in industrialized and postindustrialized countries. The cases documented the most are located mainly on Northern Atlantic coasts. This configuration makes it impossible to address coastal eutrophication issues without international regulation of exchanges and particularly salient global governance of nitrogen and phosphorus. This category shares some of the other configurations' characteristics but is unique in that it directly confronts land use and economic specialization in a globalized economy, farming practices, and managed and unmanaged primary production that overflows the land-sea divide. Thus, in coastal areas, conceptions and belief systems about nature are questioned, and contradictions between policies are highlighted, as they had been in the Great Lakes (Gould 1994). 
The main problem is that damage and responsibility are quite difficult to connect from an institutional viewpoint. Nonpoint-source pollution is thus a kind of a social and political dilemma, which becomes more complex over time (Whitney 2010). The forms of conflicts over nonpoint-source pollution from farming are diverse, but they are marked by their duration and intractability. They show the tension between commitment to a place and long-term involvement, and the dearth of political and management levers at the local scale. This brief overview reveals that it is difficult to assess how coastal eutrophication materially affects coastal people's everyday life, even in contexts of chronic dystrophic crisis: in that regard, the literature captures only a few cases in which professional, organized sectors are affected, mainly fishing, aquaculture, and tourism (e.g., French Mediterranean lagoons; Cadoret 2009). Professional mobilizations sometimes lead to recurring conflict with local authorities over various periods. Nonetheless, tourism operators, for instance, often prefer to avoid public alerts that inevitably accompany opinion enrolment (e.g., Becheri 1991), for fear of negative publicity that would affect local tourist businesses.

In a liberal and specialized economy, nonpoint-source pollution associated with global change is a factor of diffuse antagonisms and social tensions in coastal areas. The literature relates two main processes by which these stalemates may be overcome and by which people's experience regains visibility through grassroots movements. The first has been observed in industrial aquaculture areas such as the coast of Chile. Aldo Mascareño et al. (2018) show, for instance, how a red tide crisis serves as both an indicator of social-ecosystem vulnerability and as an ordeal, which can eventually give rise to organized social movements such as public protests by workers in fisheries and aquaculture (Figure 7). The second process is the development of popular epidemiology (Brown 1987), associated with health risks of micro- and macroalgal blooms, which eventually leads to recognition of human victims and to emergence of community science, like those for green tides in Brittany since 2009 (Levain 2014).

Figure 7: Protest following a massive red tide episode in Chiloé, Chile, in 2016

(৫) PiensaChile.com/T.Tricot). Reprinted with permission.

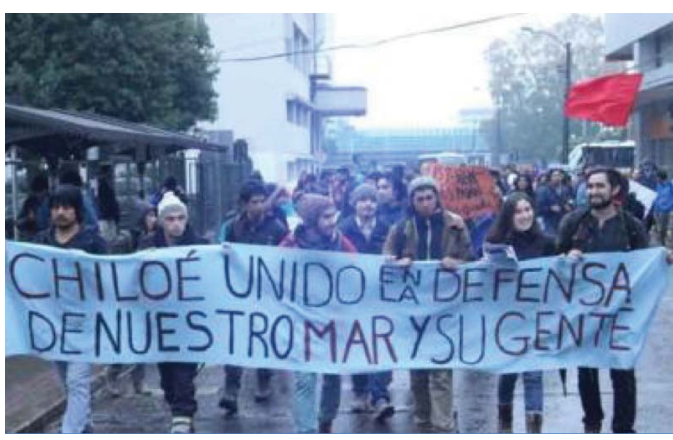

\section{Conclusion: A Dispersal Tragedy}

In this article, we initiated a dialogue between critical approaches to water and scattered empirical data that addressed the socialization of coastal eutrophication phenomena. We showed that engaging with this dialogue was a challenge for both acknowledging the complex consequences of environmental degradation on local communities and expanding critical social science's utility and concepts to address water issues within a more inclusive perspective. Indeed, as the milestones for the socio-environmental history of anthropogenic coastal eutrophication that we proposed in this article reveal, and as growing concerns and studies of ocean pollution at the global scale help realize, there is no such thing as an open ocean, but instead there are numerous epistemic, political, and cultural ordeals that weigh on the socialization of its trans-scalar properties. The wicked dimension of coastal eutrophication goes along with complex dialectics of scale and sense of place, in which the ocean first acts as a bottomless pit and a dispersal operator, and then as a fictional border that prevents coastal areas from anchoring themselves to the land. 
Indeed, coastal eutrophication makes the land-sea continuum only partially visible socially. Its management still seems to be relegated to the local scale, which is pertinent for addressing the land-sea continuum but not for addressing the major challenges of the forthcoming phosphorus scarcity crisis (Cordell and White 2011) and the unlimited input and dispersal of reactive nitrogen into the global hydro-social system. We showed that signs of expansion of hydro-social territories toward the larger ocean emerged in the early 2000s. Nonetheless, the difficulty in addressing challenges of ocean overfertilization intensifies environmental inequalities in coastal areas at both local and global scales, as our typology of hydro-social configurations shows. It also leaves unaddressed the symmetrical vulnerability of the rich, productive, but fragile coastal fringes, threatened by high inputs of terrestrial nutrients, in ways that can lead them to be assimilated into the larger, anoxic, and deep ocean.

\section{ACKNOWLEDGMENTS}

We thank Michael Corson for proofreading the English language of the manuscript and Xavier Théffo for kindly allowing us to reproduce his artistic work. We are also grateful to Chantal Gascuel, Gilles Pinay, Alain Ménesguen, and the CNRS for supporting our interdisciplinary research.

ALIX LEVAIN received her PhD from the French National Museum of Natural History and works as a social anthropologist at the CNRS. A specialist in the study of humanenvironment relations, she focuses on social experiences of environmental change in coastal socio-ecosystems. She performs fieldwork in Western Europe and East China, using both environmental anthropology and science and technology studies perspectives. From 2016 to 2018, she coordinated the social science panel of the interdisciplinary scientific expert assessment of eutrophication ordered by the French government. Email: alix.levain@univ-brest.fr

CAROLE BARTHÉLÉMY is Researcher in Environmental Sociology in the Population Environment Development Laboratory at Aix-Marseille University involved in projects on water governance, biodiversity, and urban nature. Her main expertise is in the field of interdisciplinarity between social and natural sciences. She is codirector of the Rhone Valley human-environments observatory within the LabEx DRIIHM research network.

Email: carole.barthelemy@univ-amu.fr

MAGALIE BOURBLANC is a political scientist and researcher in the French Agricultural Research and International Cooperation Organization and the Joint Research Unit "Water Management, Actors and Uses" at the University of Montpellier. She is also an extraordinary lecturer at CEEPA (Centre for Environmental Economics and Policy in Africa), University of Pretoria (South Africa). Trained as a public policy analysis specialist, she focuses on water, land, and agriculture policies in France and southern Africa, using a political ecology perspective. Recent publications include "Expert Assessment as a Framing Exercise: The Controversy over Green Macroalgal Blooms' Proliferation in France" (Science \& Public Policy, 2019) and "Political Ecologies of Water in South Africa: A Literature Review" (WIREs Water, 2019). Email: magalie.bourblanc@cirad.fr 
JEAN-MARC DOUGUET is Senior Lecturer in Economics at the Paris-Saclay University. His work is related to ecological economics and postnormal science. His research focuses on building knowledge-based partnerships for sustainable development to reintegrate economic activities into biosphere cycles, through environmental assessment, integrated analysis, and multimedia mediation of environmental knowledge. He is involved in, among other EU projects, PEGASE (Planning and Management of Water Sanitation), ALARM (Assessing Large-Scale Environmental Risks for Biodiversity with Tested Methods), and THESEUS (Innovative Technologies for Safer European Coasts in a Changing Climate). Email: jean-marc.douguet@uvsq.fr

AGATHE EUZEN is a social anthropologist whose work focuses on the social value of water and on water governance. She is currently Deputy Director of the CNRS Institute of Ecology and Environment. Email: Agathe.EUZEN@cnrs-dir.fr

YVES SOUCHON began his carrier as a fish ecologist. His applied research rapidly focused on manageable human pressures on hydrosystems: freshwater habitat and environmental flows in stream and rivers, hydromorphological alterations, and nutrient pollution. He was also involved in several expert assessments at the interface of science and policy, including the EU's Water Framework Directive and Marine Strategy Framework Directive. As a senior scientist, he is a member of the French Academy of Agriculture and of the scientific committee of the Rhône-Méditerranée-Corse Water Agency. Email: yves.souchon@inrae.fr

\section{REFERENCES}

Adger, W. Neil, Tor A. Benjaminsen, Katrina Brown, and Hanne Svarstad. 2001. "Advancing a Political Ecology of Global Environmental Discourses." Development and Change 32 (4): 681-715.

Anthony, Abigail, Joshua Atwood, Peter V. August, Carrie Byron, J. Stanley Cobb, Cheryl Foster, Crystal Fry, et al. 2009. "Coastal Lagoons and Climate Change: Ecological and Social Ramifications in the U.S. Atlantic and Gulf Coast Ecosystems." Ecology and Society 14 (1). https://www.ecologyandsoci ety.org/vol14/iss1/art8.

Arnesen, Vegard. 2001. "The Pollution and Protection of the Inner Oslofjord: Redefining the Goals of Wastewater Treatment Policy in the 20th Century." Ambio 30 (4): 282-286.

Artell, Janne, Heini Ahtiainen, and Eija Pouta. 2013. "Subjective vs. Objective Measures in the Valuation of Water Quality.” Journal of Environmental Management 130: 288-296.

Aukerman, Chantal. 2004. "Agricultural Diffuse Pollution Controls: Lessons for Scotland from the Chesapeake Bay Watershed." Journal of Land Use and Environmental Law 20 (1): 191-261.

Bakker, Karen. 2005. "Neoliberalizing Nature? Market Environmentalism in Water Supply in England and Wales." Annals of the Association of American Geographers 95 (3): 542-565.

Bakker, Karen. 2012. "Water: Political, Biopolitical, Material." Social Studies of Science 42 (4): 616-623.

Bankoff, Greg. 1999. "Societies in Conflict: Algae and Humanity in the Philippines." Environmental History 5 (1): 97-123.

Bailey, Jennifer, Murat Van Ardelan, Klaudia L. Hernandez, Humberto E. González, José Luis Iriarte, Lasse Mork Olsen, Hugo Salgado, et al. 2015. "Interdisciplinarity as an Emergent Property: The Research Project 'CINTERA' and the Study of Marine Eutrophication." Sustainability 7 (7): 9118-9139. 
Barnes, Jessica, and Samer Alatout. 2012. "Water Worlds: Introduction to the Special Issue of Social Studies of Science." Social Studies of Science 42 (4): 483-488.

Barth, Fredrik. 2002. "An Anthropology of Knowledge." Current Anthropology 43 (1): 1-18.

Barthel, Pierre-Arnaud. 2003. "Les lacs de Tunis en projets: Reflets d'un nouveau gouvernement urbain" [Developing the lakes of Tunis: A new approach in urban governance]. Annales de géographie 633: 518-536.

Becheri, Emilio. 1991. "Rimini and Co-the End of a Legend? Dealing with the Algae Effect." Tourism Management 12 (3): 229-235.

Bennett, Nathan J. 2019. "Marine Social Science for the Peopled Seas." Coastal Management 47 (2): 244-252.

Berkes, Fikret. 2015. Coasts for People: Interdisciplinary Approaches to Coastal and Marine Resource Management. London: Routledge.

Bijker, Wiebe E. 2007. "Dikes and Dams, Thick with Politics." Isis 98 (1): 109-123.

Boelens, Rutgerd. 2015. Water, Power and Identity: The Cultural Politics of Water in the Andes. London: Routledge.

Boelens, Rutgerd, Jaime Hoogesteger, Erik Swyngedouw, Jeroen Vos, and Philippus Wester. 2016. "Hydrosocial Territories: A Political Ecology Perspective." Water International 41 (1): 1-14.

Boholm, Åsa. 2003. "The Cultural Nature of risk: Can There Be an Anthropology of Uncertainty?" Ethnos 68 (2): 159-178.

Bourblanc, Magalie. 2019. "Expert Assessment as a Framing Exercise: The Controversy over Green Macroalgal Blooms' Proliferation in France.” Science and Public Policy 46 (2): 264-274.

Breitburg, Denise, Lisa A. Levin, Andreas Oschlies, Marilaure Grégoire, Francisco P. Chavez, Daniel J. Conley, Véronique Garçon, et al. 2018. "Declining Oxygen in the Global Ocean and Coastal Waters.” Science 359 (6371). https://doi.org/10.1126/science.aam7240.

Brown, Phil. 1987. "Popular Epidemiology: Community Response to Toxic Waste-Induced Disease in Woburn, Massachusetts." Science, Technology, \& Human Values 12 (3-4): 78-85.

Cadoret, Anne. 2009. "Conflict Dynamics in Coastal Zones: A Perspective Using the Example of Languedoc-Roussillon (France)." Journal of Coastal Conservation 13 (2): 151-163.

Callon, Michel. 1991. “Techno-economic Networks and Irreversibility." In A Sociology of Monsters: Essays on Power, Technology and Domination, ed. John Law, 132-161. London: Routledge.

Chevassus-au-Louis, Bernard, Bruno Andral, Alain Femenias, and Michel Bouvier. 2012. "Bilan des connaissances scientifiques sur les causes des proliférations de macroalgues vertes" [Assessment of scientific knowledge on causes for green macroalgae blooms]. Report to the French Ministries of Ecology and Agriculture. Paris: La Documentation française.

Cloern, James E. 2001. "Our Evolving Conceptual Model of the Coastal Eutrophication Problem." Marine Ecology Progress Series 210: 223-53.

Conde, Jesus E., and Gilberto Rodríguez. 1999. "Integrated Coastal Zone Management in Venezuela: The Maracaibo System.” In Perspectives on Integrated Coastal Zone Management, ed. Wim Salomons, R. Kerry Turner, Luiz Drude de Lacerda, and Sundararajan Ramachandran, 297-312. Berlin: Springer.

Cordell, Dana, and Stuart B. White. 2011. "Peak Phosphorus: Clarifying the Key Issues of a Vigorous Debate about Long-Term Phosphorus Security." Sustainability 3 (10): 2027-2049.

Dalla Bernardina, Sergio. 2010. "Les invasions biologiques sous le regard des sciences de l'homme" [Biological invasions under human and social sciences' scrutiny]. In Les invasions biologiques, une question de natures et de sociétés, ed. Robert Barbault and Martine Atramentowicz, 65-108. Paris: Quae.

D’Elia, Christopher F., Walter R. Boynton, and James G. Sanders. 2003. "A Watershed Perspective on Nutrient Enrichment, Science, and Policy in the Patuxent River, Maryland: 1960-2000." Estuaries 26 (2): 171-185.

De Jong, Folkert. 2006. Marine Eutrophication in Perspective: On the Relevance of Ecology for Environmental Policy. Berlin: Springer.

De Jong, Folkert. 2016. “Ecological Knowledge and North Sea Environmental Policies." Environmental Science and Policy 55 (3): 449-455. 
Dewey, John. 2012. The Public and Its Problems: An Essay in Political Inquiry. University Park, PA: Penn State University Press.

Diaz, Robert J., and Rutger Rosenberg. 2008. "Spreading Dead Zones and Consequences for Marine Ecosystems.” Science 321 (5891): 926-929.

Douglas, Mary, and Aron Wildavsky.1983. Risk and Culture: An Essay on the Selection of Technological and Environmental Dangers. Berkeley: University of California Press.

Elofsson, Katarina, Henk Folmer, and Marie Gren. 2003. "Management of Eutrophicated Coastal Ecosystems: A Synopsis of the Literature with Emphasis on Theory and Methodology." Ecological Economics 47 (1): 1-11.

Feldman, Kristine L., David A. Armstrong, Brett R. Dumbauld, Theodore H. DeWitt, and Daniel C. Doty. 2000. "Oysters, Crabs, and Burrowing Shrimp: Review of an Environmental Conflict over Aquatic Resources and Pesticide Use in Washington State's (USA) Coastal Estuaries." Estuaries 23 (2): 141-176.

Finni, Terttu, Kaisa Kononen, Riitta Olsonen, and Kerstin Wallström. 2001. “The History of Cyanobacterial Blooms in the Baltic Sea." Ambio 30 (4): 172-178.

Forsyth, Timothy. 2004. Critical Political Ecology: The Politics of Environmental Science. London: Routledge.

Francis, George R. 1988. "Institutions and Ecosystem Redevelopment in Great Lakes America with Reference to Baltic Europe.” Ambio 17 (2): 106-111.

Franzén, Frida, Gerda Kinell, Jakob Walve, Ragnar Elmgren, and Tore Söderqvist. 2011. "Participatory Social-Ecological Modeling in Eutrophication Management: The Case of Himmerfärden, Sweden.” Ecology and Society 16 (4).

Freeman, David M. 2000. "Wicked Water Problems: Sociology and Local Water Organizations in Addressing Water Resources Policy." Journal of the American Water Resources Association 36 (3): 483-491.

Freitag, Amy. 2014. "Naming, Framing, and Blaming: Exploring Ways of Knowing in the Deceptively Simple Question 'What Is Water Quality?’” Human Ecology 42 (2): 325-337.

Gao, Chao, and Taolin Zhang. 2010. "Eutrophication in a Chinese Context: Understanding Various Physical and Socio-economic Aspects." Ambio 39 (5-6): 385-393.

Geels, Frank W. 2004. "From Sectoral Systems of Innovation to Socio-technical Systems: Insights about Dynamics and Change from Sociology and Institutional Theory." Research Policy 33 (6-7): 897-920.

Gieryn, Thomas F. 1983. "Boundary-Work and the Demarcation of Science from Non-science: Strains and Interests in Professional Ideologies of Scientists.” American Sociological Review 48 (6): 781-795.

Giglioli, Ilaria, and Erik Swyngedouw. 2008. "Let's Drink to the Great Thirst! Water and the Politics of Fractured Techno-natures in Sicily." International Journal of Urban and Regional Research 32 (2): 392-414.

Glibert, Patricia M., Adnan Al-Azri, J. Icarus Allen, Alexander F. Bouwman, Arthur H. W. Beusen, Michele A. Burford, Paul J. Harrison, et al. 2018. "Key Questions and Recent Research Advances on Harmful Algal Blooms in Relation to Nutrients and Eutrophication.” In Global Ecology and Oceanography of Harmful Algal Blooms, ed. Patricia M. Glibert, Elisa Berdalet, Michele A. Burford, Grant C. Pitcher, and Mingjiang Zhou, 229-259. Cham: Springer.

Gould, Kenneth A. 1993. "Pollution and Perception: Social Visibility and Local Environmental Mobilization.” Qualitative Sociology 16 (2): 157-178.

Gould, Kenneth A. 1994. "Legitimacy and Growth in the Balance: The Role of the State in Environmental Remediation.” Industrial \& Environmental Crisis Quarterly 8 (3): 237-256.

Gruber, Nicolas, and James N. Galloway. 2008. "An Earth-System Perspective of the Global Nitrogen Cycle." Nature 451 (7176): 293-296.

Gusfield, Joseph R. 1984. The Culture of Public Problems: Drinking-Driving and the Symbolic Order. Chicago: University of Chicago Press.

Hänninen, Sakari. 1992. "How to Combat Pollution by Words." Alternatives: Global, Local, Political 17 (2): 209-229.

Helmreich, Stefan. 2011. "Nature/Culture/Seawater." American Anthropologist 113 (1): 132-144. 
Isaacson, Robert L., and Milton L. Blum. 1967. Psychology: The Science of Behavior. New York: Harper \& Row.

Jentoft, Svein, and Ratana Chuenpagdee. 2009. “Fisheries and Coastal Governance as a Wicked Problem." Marine Policy 33 (4): 553-560.

Jepson, Michael. 2007. "Social Indicators and Measurements of Vulnerability for Gulf Coast Fishing Communities." NAPA Bulletin 28: 57-68.

Jepson, Wendy, and Christian Brannstrom. 2016. "Techno-nature and Scaling Water Governance in South Texas." In Negotiating Water Governance: Why the Politics of Scale Matter, ed. Emma S. Norman, Christina Cook, and Alice Cohen, 155-173. London: Routledge.

Jönsson, Anna Maria. 2011. "Framing Environmental Risks in the Baltic Sea: A News Media Analysis." Ambio 40 (2): 121-132.

Kehoe, Terence. 1992. "Merchants of Pollution? The Soap and Detergent Industry and the Fight to Restore Great Lakes Water Quality, 1965-1972.” Environmental History Review 16 (3): 21-46.

Kermagoret, Charlène, Joachim Claudet, Valérie Derolez, Maggy M. Nugues, Vincent Ouisse, Nolwenn Quillien, Yoann Baulaz, et al. 2019. "How Does Eutrophication Impact Bundles of Ecosystem Services in Multiple Coastal Habitats Using State-and-Transition Models." Ocean \& Coastal Management 174: 144-153.

Kim, Seoyong. 2003. "Irresolvable Cultural Conflicts and Conservation/Development Arguments: Analysis of Korea's Saemangeum Project." Policy Sciences 36 (2): 125-149.

Kitsiou, Dimitra, and Michael Karydis. 2011. "Coastal Marine Eutrophication Assessment: A Review on Data Analysis." Environmental International 37 (4): 778-801.

Krause, Franz, and Veronica Strang. 2016. “Thinking Relationships through Water.” Society \& Natural Resources 29 (6): 633-638.

Laakkonen, Simo, and Sari Laurila. 2007. "Changing Environments or Shifting Paradigms? Strategic Decision Making toward Water Protection in Helsinki, 1850-2000.” Ambio 36 (2-3): 212-219.

Larson, Douglas W. 1996. “Curing the Incurable?” American Scientist 84 (1): 7-9.

Le Chêne, Monique. 2012. "Algues vertes, terrain glissant” [Green algae, slippery ground]. Ethnologie française 42 (4): 657-665.

Le Moal, Morgane, Chantal Gascuel-Odoux, Alain Ménesguen, Yves Souchon, Claire Étrillard, Alix Levain, Florentina Moatar, Alexandrine Pannard, et al. 2019. "Eutrophication: A New Wine in an Old Bottle?" Science of the Total Environment 651: 1-11.

Levain, Alix. 2013. "Faire face aux marées vertes, penser les crises du vivant" [Facing "green tides," thinking crisis of living beings]. Ethnographiques.org 27.

Levain, Alix. 2014. "Living with Green Algae: Mediations, Ordeals and Signs." PhD diss., Muséum National d'Histoire Naturelle.

Levain, Alix. 2017. "Hǔtái, une sortie de l’insignifiance: L'apparition des marées vertes en baie de Qingdao" [Coming out of insignificance: The apparition of green tides in Qingdao Bay]. Techniques \& Culture 68 (2): 66-83.

Levain, Alix, Carole Barthélémy, Magalie Bourblanc, Jean-Marc Douguet, and Agathe Euzen. 2017. "Social and Political Dynamics Associated with Eutrophication Issues and Their Management." In Eutrophication: Manifestations, Causes, Consequences and Predictability, ed. CNRS: IfremerInra-Irstea, 949-1129. Report to the Ministries of Environment and Agriculture, Paris.

Levain, Alix, and Pauline Laval. 2018. "Jusqu’où va la mer? Une exploration des marges de l'anthropologie maritime" [How far does the sea go? Exploring the margins of maritime anthropology]. Revue d'ethnoécologie 13. https://doi.org/10.4000/ethnoecologie.3449.

Levieil, Dominique P., and Benjamin Orlove. 1990. "Local Control of Aquatic Resources: Community and Ecology in Lake Titicaca, Peru.” American Anthropologist 92 (2): 362-382.

Levin, Lisa A. 2018. "Manifestation, Drivers, and Emergence of Open Ocean Deoxygenation." Annual Review of Marine Science 10 (1): 229-260.

Linke, Sebastian, Michael Gilek, Mikael Karlsson, and Oksana Udovyk. 2014. “Unravelling SciencePolicy Interactions in Environmental Risk Governance of the Baltic Sea: Comparing Fisheries and Eutrophication." Journal of Risk Research 17 (4): 505-523. 
Linton, Jamie, and Jessica Budds. 2014. "The Hydrosocial Cycle: Defining and Mobilizing a RelationalDialectical Approach to Water." Geoforum 57: 170-180.

Longo, Stefano B., Rebecca Clausen, and Brett Clark, eds. 2015. The Tragedy of the Commodity: Oceans, Fisheries, and Aquaculture. New Brunswick, NJ: Rutgers University Press.

Löwgren, Marianne, Thomas Hillmo, and Ulrik Lohm. 1989. "Water Pollution Perspectives: Problem Conceptualizations and Abatement Strategies in Sweden during the 20th Century." GeoJournal 19 (2): 161-71.

Lundberg, Cecilia. 2013. "Eutrophication, Risk Management and Sustainability: The Perceptions of Different Stakeholders in the Northern Baltic Sea." Marine Pollution Bulletin 66 (1-2): 143-150.

Lyytimäki, Jari. 2012. "Gone with the Wind? Newspaper Discourse of Eutrophication and Blue-Green Algae Blooms in Finland." Water and Environment Journal 26 (3): 405-414.

Lyytimäki, Jari, and Timo Assmuth. 2015. "Down with the Flow: Public Debates Shaping the Risk Framing of Artificial Groundwater Recharge." GeoJournal 80 (1): 113-127.

Mascareño, Aldo, Rodrigo Cordero, Gabriela Azócar, Marco Billi, Pablo A. Henríquez, and Gonzalo A. Ruz. 2018. "Controversies in Social-Ecological Systems: Lessons from a Major Red Tide Crisis on Chiloe Island, Chile." Ecology and Society 23 (4): https://doi.org/10.5751/ES-10300-230415.

Mazé, Camille, Tarik Dahou, Olivier Ragueneau, Anatole Danto, Emilie Mariat-Roy, Mélanie Raimonet, and Julien Weisbein. 2017. "Knowledge and Power in Integrated Coastal Management: For a Political Anthropology of the Sea Combined with the Sciences of the Marine Environment." Comptes Rendus Geoscience 349 (6-7): 359-368.

Ménesguen, Alain. 2018. Les marées vertes: 40 clés pour comprendre [Green tides: 40 keys to understand]. Paris: Quae.

Millennium Ecosystem Assessment. 2005. Ecosystems and Human Well-Being: General Synthesis. Washington, DC: Island Press.

Mollinga, Peter. 2008. "Water, Politics and Development: Framing a Political Sociology of Water Resources Management.” Water Alternatives 1 (1): 7-23.

Morand, Philippe. 2005. "Macroalgal Population and Sustainability." Journal of Coastal Research 21 (5): 1009-1020.

Moser, Gabriel, Eugenia Ratiu, and Bernadette De Vanssay. 2004. "Water Use and Management in the Light of Sustainable Development." IHDP Update 4: 13-15.

Nelkin, Dorothy. 1976. "Ecologists and the Public Interest." Hastings Center Report 6 (1): 38-44.

Nixon, Scott W. 2009. "Eutrophication and the Macroscope." Hydrobiologia 629 (5): 5-19.

Nunneri, Corina, and Jürgen Hofmann. 2005. "A Participatory Approach for Integrated River Basin Management in the Elbe Catchment." Estuarine, Coastal and Shelf Science 62 (3): 521-537.

Paerl, Hans W., Timothy G. Otten, and Raphael Kudela. 2018. "Mitigating the Expansion of Harmful Algal Blooms Across the Freshwater-to-Marine Continuum." Environmental Science \& Technology 52 (10): 5519-5529.

Paolisso, Michael, Jeremy Trombley, Raleigh R. Hood, and Kevin G. Sellner. 2015. “Environmental Models and Public Stakeholders in the Chesapeake Bay Watershed." Estuaries and Coasts 38 (1): 97-113.

Paolisso, Michael, and R. Shawn Maloney. 2000. "Recognizing Farmer Environmentalism: Nutrient Runoff and Toxic Dinoflagellate Blooms in the Chesapeake Bay Region.” Human Organization 59 (2): 209-221.

Peluso, Nancy L. 2012. "What's Nature Got To Do With It? A Situated Historical Perspective on Socio-Natural Commodities." Development and Change 43 (1): 79-104.

Pittman, Jeremy, and Derek Armitage. 2016. "Governance across the Land-Sea Interface: A Systematic Review." Environmental Science \& Policy 64: 9-17.

Pokrant, Bob, and Laura Stocker. 2011. "Anthropology, Climate Change and Coastal Planning." In Environmental Anthropology Today, ed. Helen Kopnina and Eleanor Shoreman-Ouimet, 179-194. London: Routledge.

Rabalais, Nancy N., R. Eugene Turner, Robert J. Díaz, and Dubravko Justić. 2009. "Global Change and Eutrophication of Coastal Waters.” ICES Journal of Marine Science 66 (7): 1528-1537. 
Rittel, Horst W. J., and Melvin M. Webber. 1973. “Dilemmas in a General Theory of Planning.” Policy Sciences 4 (2): 155-169.

Robbins, Paul, John Hintz, and Sarah A. Moore, eds. 2014. Environment and Society: A Critical Introduction. Bridgewater: Wiley \& Sons.

Rockström, Johan, W. L. Steffen, Kevin Noone, Åsa Persson, F. Stuart Chapin III, Eric Lambin, Timothy M. Lenton, et al. 2009. "Planetary Boundaries: Exploring the Safe Operating Space for Humanity." Ecology and Society 14 (2). https://pdxscholar.library.pdx.edu/iss_pub/64.

Rosa, Eugene A.1998. "Metatheoretical foundations for post-normal risk." Journal of Risk Research 1 (1): $15-44$.

Sauvageau, Camille. 1920. L'utilisation des algues marines [The uses of marine algae]. Paris: Gaston Doin.

Schneider, Daniel W. 2000. "Local Knowledge, Environmental Politics, and the Founding of Ecology in the United States: Stephen Forbes and 'The Lake as a Microcosm' (1887)." Isis 91 (4): 681-705.

Shackeroff, Janna M., Lisa M. Campbell, and Larry B. Crowder. 2011. "Social-Ecological Guilds: Putting People into Marine Historical Ecology." Ecology and Society 16 (1). http://www.ecologyandsociety .org/vol16/iss1/art52.

Söderqvist, Tore. 1998. "Why Give up Money for the Baltic Sea? Motives for People's Willingness (or Reluctance) to Pay." Environmental and Resource Economics 12 (2): 249-254.

Steffen, Will, Katherine Richardson, Johan Rockström, Sarah E. Cornell, Ingo Fetzer, Elena M. Bennett, Reinette Biggs, et al. 2015. "Planetary Boundaries: Guiding Human Development on a Changing Planet." Science 347 (6223). https://doi.org/10.1126/science.1259855.

Steinberg, Philip E. 2001. The Social Construction of the Ocean. Cambridge: Cambridge University Press.

Strang, Veronica. 2013. "Going against the Flow: The Biopolitics of Dams and Diversions." Worldviews: Global Religions, Culture, and Ecology 17 (2): 161-173.

Strang, Veronica. 2015. Water: Nature and Culture. London: Reaktion Books.

Swyngedouw, Erik. 2009. “The Political Economy and Political Ecology of the Hydro-social Cycle." Journal of Contemporary Water Research \& Education 142 (1): 56-60.

Thornton, Jeffrey A., William R. Harding, Mark Dent, Rob C. Hart, Hebin Lin, Claudia L. Rast, Walter Rast, et al. 2013. "Eutrophication as a 'Wicked' Problem." Lakes \& Reservoirs: Research \& Management 18 (4): 298-316.

Ulén, Barbro M., and Gesa Weyhenmeyer. 2007. "Adapting Regional Eutrophication Targets for Surface Waters: Influence of the EU Water Framework Directive, National Policy and Climate Change." Environmental Science \& Policy 10 (7-8): 734-742.

UN. 2017. The First Global Integrated Marine Assessment. Cambridge: Cambridge University Press.

Whitney, Kristoffer. 2010. "Living Lawns, Dying Waters: The Suburban Boom, Nitrogenous Fertilizers, and the Nonpoint Source Pollution Dilemma." Technology and Culture 51 (3): 652-674.

Willis, Cheryl, Eleni Papathanasopoulo, Duncan Russel, and Yuri Artioli. 2018. "Harmful Algal Blooms: The Impacts on Cultural Ecosystem Services and Human Well-Being in a Case Study Setting, Cornwall, UK." Marine Policy 97: 232-238.

Zimmerer, Karl S. 2011. "Spatial-geographic Models of Water Scarcity and Supply in Irrigation Engineering and Management. Bolivia, 1952-2009." In Knowing Nature, Conversations at the Intersection of Political Ecology and Science Studies, ed. Mara J. Goldman, Paul Nadasdy, and Matthew D. Turner, 167-185. Chicago: University of Chicago Press.

Zinia, Naeema Jihan, and Carolien Kroeze. 2015. "Future Trends in Urbanization and Coastal Water Pollution in the Bay of Bengal: The Lived Experience." Environment, Development and Sustainability 17 (3): 531-546. 